\title{
Infarto perioperatorio en cirugía no-cardíaca y dexmedetomidina
}

\author{
Mauricio Ibacache ${ }^{1,2}$, Zully Pedrozo², Carolina Fernández², Gina Sánchez ${ }^{2,3}$, Sergio \\ Lavandero ${ }^{2,3,4}$. \\ ${ }^{1}$ Departamento de Anestesiología, Facultad de Medicina, Pontificia Universidad Católica \\ de Chile. ${ }^{2}$ Centro FONDAP Estudios Moleculares de la Célula. ${ }^{3}$ Departamento de \\ Bioquímica y Biología Molecular, Facultad de Ciencias Químicas y Farmacéuticas, \\ ${ }^{4}$ Instituto de Ciencias Biomédicas, Facultad de Medicina, Universidad de Chile, Santiago, \\ Chile. \\ Este trabajo fue financiado en parte por Proyecto FONIS SA091236 (M.I), FONDECYT-1080447 \\ (G.S.) y FONDAP 15010006 (S.L.) \\ Recibido el 2 de Enero de 2010, Aceptado el 5 de Marzo de 2010.
}

Rev Chil Cardiol 2010; 29: 100-116

\section{Resumen}

La patología cardiovascular es la primera causa de muerte en Chile y en el mundo. Desde el punto de vista quirúrgico, anestesiólogos y cirujanos enfrentan más frecuentemente pacientes mayores con patología cardiovascular. La incidencia de isquemia miocárdica en pacientes de alto riesgo, sometidos a cirugía no-cardíaca, es cercana al $40 \%$ durante el perioperatorio. La incidencia de infarto miocárdico y muerte en cirugía no-cardíaca, oscila entre 1 y 5\%. Existe una estrecha relación entre los eventos isquémicos perioperatorios y el aumento de la morbimortalidad cardiovascular. Por este motivo, se han desarrollado medidas terapéuticas orientadas a disminuir la incidencia de isquemia perioperatoria y aminorar el daño asociado a ella. La adecuada identificación de pacientes de riesgo, la optimización del tratamiento médico de patologías asociadas y el uso de fármacos cardioprotectores durante el perioperatorio, han mostrado disminuir la incidencia de complicaciones cardíacas.

Dexmedetomidina es un agonista $\alpha_{2}$-adrenérgico de uso frecuente en anestesia. La evidencia sugiere que posee propiedades cardioprotectoras que podrían beneficiar a pacientes quirúrgicos de alto riesgo cardiovascular. La cardioprotección conferida por dexmedetomidina estaría mediada por la modulación del sistema nervioso autónomo. La disminución de la frecuencia cardíaca y de la presión arterial observada durante su uso, evitarían el desbalance entre aporte y demanda de oxígeno miocárdico y atenuarían el estrés sobre placas ateromatosas inestables. Hasta este momento se desconoce si dexmedetomidina produce precondicionamiento cardíaco y si activa vías transduccionales asociadas a cardioprotección. Frente a la actual realidad epidemiológica en Chile y el mundo, es importante estudiar y definir, cuales son

Correspondencia: Dr. Mauricio Ibacache

Departamento de Anestesiología, Facultad deMedicina,

Pontificia Universidad Católica de Chile

Marcoleta 367, Santiago - Fono: 8330024 - Fax: 6327620

Correo Electrónico: mibacache@med.puc.cl

o Dr. Sergio Lavandero, Facultad de Ciencias Químicas y

Farmacéuticas, Universidad de Chile

Olivos 1007, Santiago - Fono: 8380492 - Fax:978 2912

Correo Electrónico: slavander@uchile.cl 
M. Ibacache, Z. Pedrozo, C. Fernández, G. Sánchez, S. Lavandero.

los fármacos de uso frecuente en anestesia con capacidad cardioprotectora y los mecanismos involucrados en esta protección. Sería interesante lograr dicha definición respecto del uso perioperatorio de dexmedetomidina.

\section{Perioperative myocardical infaction in non-cardiac surgery and dexmedetomidine}

Cardiovascular disease is the leading cause of death in Chile and worldwide. Anesthesiologists and surgeons often face more elderly surgical patients with cardiovascular disease. The incidence of myocardial ischemia in patients at high risk, undergoing non-cardiac surgery is about $40 \%$ during the perioperative period. The incidence of myocardial infarction and death in non-cardiac surgery is between 1 and $5 \%$. There is a close relationship between perioperative ischemic events and increased cardiovascular morbidity and mortality. Therefore, therapeutic approaches have been developed to reduce the incidence of perioperative ischemia and lessen the damage associated with it. The proper identification of patients at risk, optimizing the medical treatment of associated diseases and the use of cardioprotective drugs during the perioperative period have shown to decrease the incidence of cardiac complications.

The $\alpha_{2}$-adrenergic agonist dexmedetomidine is commonly used in anesthesia. The evidence suggests that possesses cardioprotective properties that could benefit surgical patients at high cardiovascular risk. The cardioprotection conferred by dexmedetomidine would be mediated by modulation of the autonomic nervous system. The decrease in heart rate and blood pressure observed during its use could avoid the imbalance between supply and myocardial oxygen demand and lessen the stress on unstable atheromatous plaques. So far it is unknown whether or not dexmedetomidine produces cardiac preconditioning by activating cardioprotective signaling pathways.

Faced with the current worldwide epidemiologic situation, it would be important to study the cardioprotective capacity of drugs frequently used in anesthesia and the mechanisms involved in that protection. It would be interesting to achieve that definition regarding the perioperative use of dexmedetomidine.

Key Words: perioperative ischemia, a2 - adrenergic agonist, cardioprotection, dexmedetomidine, Myocardial infarction, beta-adrenergic receptor.

\section{Introducción}

\section{Complicaciones perioperatorias}

En países desarrollados, un elevado porcentaje de los pacientes adultos que enfrentan una cirugía corresponden a enfermos coronarios ${ }^{1}$. Si analizamos las complicaciones cardiovasculares que ocurren en estos pacientes, la gran mayoría tiene relación con enfermedad coronaria preexistente. Se ha descrito que alrededor del 1 al $5 \%$ de los pacientes sometidos a cirugía presentan eventos cardiovasculares graves tales como: muerte de causa cardíaca, infarto del miocardio, arritmias e insuficiencia cardíaca ${ }^{2,3}$. En pacientes con elevado riesgo cardiovascular, algunos investigadores han descrito incidencias cercanas al $34 \%$ para este tipo de eventos ${ }^{4}$. En Chile, no se cuenta con estadísticas respecto de esta situación, pero tomando en cuenta los antecedentes epidemiológicos disponibles, es poco probable que la incidencia de enfermedad coronaria, de isquemia perioperatoria y de eventos cardiovasculares perioperatorios, sean inferiores a 
las descritas internacionalmente. En nuestro país, la mortalidad por causa cardiovascular se ubica en primer lugar y corresponde aproximadamente al $27 \%$ de las muertes totales ${ }^{5}$. La enfermedad coronaria corresponde al $36 \%$ de las muertes de causa circulatoria y es causa de muerte en aproximadamente el $8 \%$ de la población chilena ${ }^{5,6}$. Dos aspectos preocupantes durante las últimas décadas son: el aumento de la prevalencia de factores de riesgo asociados a enfermedad cerebrovascular y coronaria, en los menores de 50 años $^{7-9}$ y el acelerado envejecimiento de la población chilena. Este último hecho es de la mayor relevancia en las proyecciones de muerte de causa cardiovascular, puesto que el crecimiento en edad se asocia al desarrollo de patologías crónicas predisponentes tales como: aterosclerosis y enfermedad coronaria.

\section{Manejo perioperatorio}

Los hechos descritos han motivado que investigadores y médicos se focalicen en el estudio del riesgo cardiovascular perioperatorio, con el propósito de evitar o disminuir la ocurrencia de complicaciones cardiovasculares. En este sentido, el American College of Cardiology y la American Heart Association (ACC/AHA) han generando las Guías de Evaluación Cardiovascular y Cuidados Perioperatorios para Cirugía No-Cardíaca, cuya última actualización se realizó en el año $2007^{10}$. Estas guías entregan una base sólida para la estratificación de pacientes quirúrgicos, mediante la identificación de factores de riesgo cardiovascular específicos y la evaluación de su estado funcional. Proponen una serie de algoritmos de toma de decisiones, relacionados con el estudio y manejo preoperatorio de estos pacientes. Las medidas orientadas a disminuir la ocurrencia de eventos de isquemia miocárdica perioperatoria y sus complicaciones cardiovasculares asociadas, son: 1) una acertada determinación del riesgo perioperatorio para cada paciente particular, 2) optimizar el tratamiento médico perioperatorio, 3) una adecuada monitorización cardiovascular perioperatoria y 4) definir la necesidad de revascularización miocárdica preoperatoria. En relación al tratamiento médico preoperatorio de patologías preexistentes, se recomienda que al momento de enfrentar una cirugía, las enfermedades concomitantes estén compensadas y en tratamiento. El otro aspecto fundamental del manejo médico, hace referencia al uso perioperatorio de fármacos con propiedades cardioprotectoras. Las guías del ACC/AHA recomiendan el uso de bloqueadores $\beta$-adrenérgicos en determinados pacientes sometidos a cirugía. Sin embargo, actualmente la indicación perioperatoria de $\beta$-bloqueadores está siendo cuestionada y es materia de una profunda revisión debido al aumento de complicaciones cerebrovasculares asociadas a su uso perioperatorio ${ }^{11}$. Pareciera ser que los $\beta$-bloqueadores son útiles $\mathrm{y}$ beneficiosos durante el perioperatorio en un grupo reducido de pacientes con alto riesgo cardiovascular ${ }^{10}$. El uso de estatinas en pacientes de riesgo intermedio y alto es recomendado. No sólo mejorarían el perfil lipídico de estos pacientes, evitando el crecimiento de placas de ateroma, sino que también mejoraría la función endotelial, disminuiría la inflamación y estabilizaría las placas en riesgo de accidentarse. Diversos estudios y meta-análisis han mostrado que la mantención de este tipo de fármacos durante el perioperatorio disminuye la incidencia de complicaciones cardiovasculares ${ }^{12,13}$. Sin embargo, la administración aguda en el escenario quirúrgico aún es controversial. Los agonistas $\alpha_{2}$-adrenérgicos son otro grupo de fármacos que aparecen útiles en la terapia perioperatoria de pacientes coronarios o con factores de riesgo cardiovascular que requieren control de hipertensión perioperatoria ${ }^{10}$. Algunos estudios sugieren que clonidina, mivazerol y dexmedetomidina, disminuyen la incidencia de isquemia y las complicaciones cardiovasculares asociadas a ella, mejorando la sobrevida a largo plazo ${ }^{14-16}$. Los agonistas $\alpha_{2}{ }^{-}$ 
adrenérgicos son fármacos de uso cada vez más frecuente en el ámbito anestésico, especialmente desde la introducción de la dexmedetomidina en el armamentario farmacológico. Producen sedación y analgesia, siendo empleados con éxito como coadyuvantes anestésicos y en sedación intra y postoperatoria de pacientes críticos ${ }^{17}$.

En un momento en que el uso agudo de $\beta$-bloqueadores y estatinas durante el perioperatorio es cuestionado, parece interesante definir los potenciales beneficios cardiovasculares de los agonistas $\alpha_{2}$-adrenérgicos en este período. El propósito de este artículo es revisar los mecanismos fisiopatológicos y moleculares involucrados en el daño miocárdico perioperatorio por isquemia y reperfusión, describir las maniobras disponibles de cardioprotección y comentar la evidencia experimental y clínica acerca de la utilidad del agonista $\alpha_{2}$-adrenérgico dexmedetomidina durante cirugía no-cardíaca.

\section{Daño miocárdico perioperatorio \\ Isquemia versus infarto del miocardio}

La isquemia miocárdica se define como un desbalance entre el aporte y la demanda de oxígeno y nutrientes en un determinado territorio del corazón. Si la isquemia es limitada en el tiempo, al ser tratada o al resolverse en forma espontánea, se evitará el daño y la muerte de cardiomiocitos. El daño irreversible de éstos depende de la duración de la isquemia y de las alteraciones moleculares que ocurren durante este período, como también de las alteraciones generadas durante la reperfusión de los territorios afectados. La mayor o menor sobrevida de cardiomiocitos durante eventos isquémicos dependerá de la magnitud del daño generado por el proceso de isquemia-reperfusión y de la capacidad del miocardio de gatillar vías moleculares de sobrevida celular. Entendemos por infarto del miocardio a la ocurrencia de muerte de células cardíacas como consecuencia de una isquemia prolongada o no resuelta. Después del comienzo de la isquemia, la muerte celular no ocurre inmediatamente; se acepta que si la isquemia se mantiene por sobre $20 \mathrm{~min}$, es probable que el daño se haga evidente en pocas horas posterior al inicio de ésta. El tamaño del infarto depende de la cantidad de territorio isquémico, la duración de la isquemia, la presencia de circulación colateral y de la capacidad del miocardio de generar una respuesta de sobrevida frente a la injuria. Tradicionalmente, el diagnóstico de infarto se fundamenta en una sintomatología característica, criterios electrocardiográficos conocidos y elevación de enzimas cardíacas. Sin embargo, el diagnóstico del infarto perioperatorio se dificulta debido a la ausencia de síntomas en pacientes bajo la influencia de fármacos analgésicos y anestésicos. En este contexto, la determinación de troponinas cardíacas ha venido a cambiar la definición de infarto perioperatorio que en la actualidad se basa en la elevación de enzimas cardíacas en relación a la presencia de eventos isquémicos diagnosticados mayoritariamente por alteraciones electrocardiográficas características tales como: infradesnivel del segmento ST e inversión de onda T. Estudios con troponinas seriadas en pacientes de riesgo cardiovascular demuestran que el grueso de los infartos perioperatorios corresponden a infartos no-Q, que ocurren entre el primer y tercer día postoperatorios, con directa relación a la incidencia de procesos isquémicos durante ese período ${ }^{18-21}$. Fisiopatológicamente se reconocen dos mecanismos probables para la ocurrencia de infartos perioperatorios ${ }^{22}$. Tipo 1: corresponden a un síndrome coronario agudo, secundario a accidentes de placas inestables. Tipo 2: corresponden a episodios isquémicos repetidos, no resueltos en el tiempo y que se relacionan a la aparición de circunstancias perioperatorias que propician un desbalance entre el aporte y la demanda del oxígeno miocárdico. Estas circunstancias predisponentes de eventos de isquemia son: taquicardia, hipotensión, hipercoagulabilidad, disminución del transporte de oxígeno, etc. (Figura 1). 


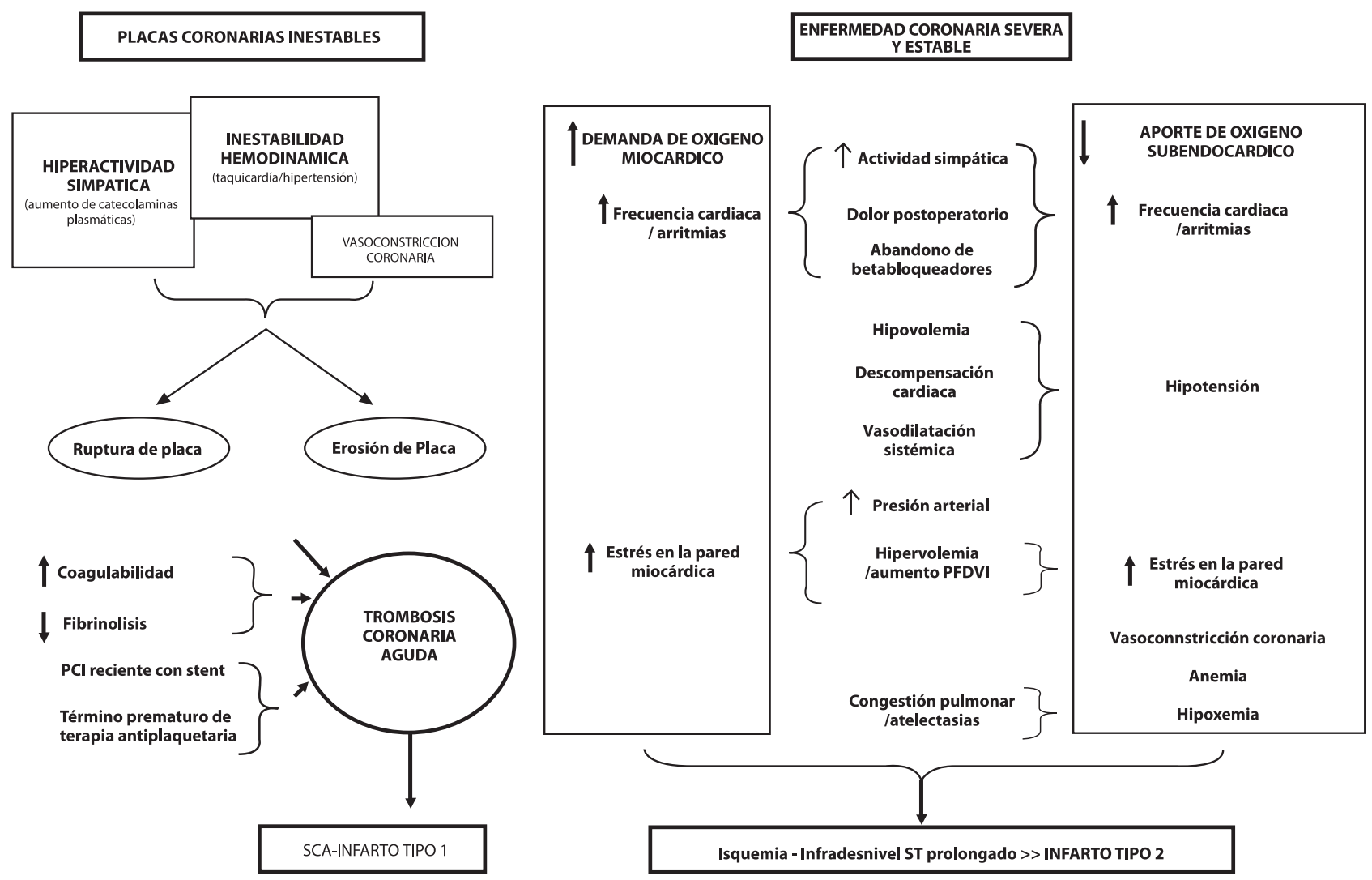

Figura 1: Mecanismos del infarto perioperatorio

Actualmente no existe consenso acerca cuál de los dos mecanismos es más frecuente. Es muy probable que en el contexto quirúrgico de un paciente de riesgo cardiovascular siempre existan procesos de isquemia perioperatoria que al no ser tratados resultarán en la aparición de un infarto tipo 1. Sin embargo, de existir en el mismo paciente placas ateromatosas inestables, es probable que frente a las mismas condiciones propiciadoras de isquemia, ocurra un infarto tipo 2 .

Desde hace tiempo, sabemos que la incidencia de complicaciones cardiovasculares en el escenario quirúrgico se relaciona directamente con la cantidad y duración de eventos isquémicos durante el período perioperatorio. Esta relación es especialmente cierta para la isquemia que ocurre durante el postoperatorio, que al compararse con las isquemias que ocurren durante los períodos pre e intraoperatorio, se asocia en mayor medida con la ocurrencia de eventos cardiovasculares graves ${ }^{23,24}$. Dependiendo del estudio, la incidencia de isquemia cardíaca durante el perioperatorio oscila entre un $15 \%$ y un $70 \%{ }^{25-27}$. Landesberg et al demostraron que el 85 $\%$ de las complicaciones cardiovasculares eran precedidas por infradesniveles del segmento $\mathrm{ST}^{23}$. Fleisher et al, mostraron que un $78 \%$ de los pacientes que se complicaban desde el punto de vista cardiovascular, tenían al menos un evento de isquemia mayor a $30 \mathrm{~min}^{28}$. Las isquemias con elevación del segmento ST son infrecuentes en el perioperatorio y no superan el $12 \%{ }^{29}$. Más recientemente, se ha demostrado que cerca de un 45 a $55 \%$ de los infartos perioperatorios fatales, tienen evidencia de accidentes de placas ateromatosas ${ }^{30}$.

No cabe duda que uno de los desafíos futuros más importantes será definir la existencia de placas ateromatosas en un paciente de riesgo coronario y precisar cuáles de esas placas son inestables y 
susceptibles de accidentarse durante el período perioperatorio.

\section{Aspectos moleculares del daño por isquemia/ reperfusión}

Breves períodos de isquemia son tolerados por los cardiomiocitos sin producir su muerte; etapa que se conoce como la fase reversible de la isquemia. Sin embargo, en la fase irreversible, tiempos prolongados de isquemia producen un daño irreparable y muerte del cardiomiocito ${ }^{31,32}$. La isquemia reversible provoca diversos cambios en los cardiomiocitos tales como: alteraciones de la contracción, disminución del ATP y del pool de nucleótidos, depleción del glicógeno, acumulación de lactato y $\mathrm{H}^{+}$, y eventualmente edema intracelular. Estas alteraciones revierten cuando el flujo coronario se restablece en los territorios isquémicos ${ }^{32,33}$. Durante la isquemia, la ausencia de oxígeno o su escasa presencia en los tejidos, determina que el metabolismo aeróbico mitocondrial cese y se inicie un metabolismo anaeróbico glicolítico. La demanda energética del cardiomiocito supera el aporte energético de la glicólisis anaeróbica y las reservas energéticas de la célula. Posteriormente, la cantidad de ATP disminuye progresivamente y se acumula ADP. La acumulación de lactato y la disminución del $\mathrm{pH}$ intracelular por acumulación de protones, inhiben la glicólisis. La contracción miocárdica disminuye con cada sístole hasta desaparecer del todo. Se produce además, una sobrecarga de osmolitos activos tales como: lactato, fosfato inorgánico y creatinina, lo cual no se traduce necesariamente en una entrada excesiva de agua y edema celular, debido a la poca disponibilidad de ésta en el espacio extracelular. El exceso de ADP generado se degrada a AMP y éste, a su vez, en adenosina. Esta última difunde al extracelular, perdiéndose cerca del $30-40 \%$ del pool de adenosina intracelular al final de la fase reversible de la isquemia.

$\mathrm{El} \mathrm{Ca}^{2+}$ libre intracelular se eleva en las etapas tardías de la fase reversible de la isquemia, provocando hipercontractura miocárdica. La isquemia provoca acidosis metabólica y activación del intercambiador $\mathrm{Na}^{+} / \mathrm{H}^{+}$, transportando protones fuera de la célula y $\mathrm{Na}^{+}$ hacia el interior. El intercambiador $\mathrm{Na}^{+} / \mathrm{Ca}^{2+}$ se activa, llevando $\mathrm{Na}^{+}$al extracelular y $\mathrm{Ca}^{2+}$ hacia el citosol. El $\mathrm{Ca}^{2+}$ también aumenta por depolarización del potencial de membrana que permite la apertura de canales de $\mathrm{Ca}^{2+}$ tipo $\mathrm{L}$ con una subsecuente mayor entrada de $\mathrm{Ca}^{2+}$. Proteínas como la superóxido dismutasa, "heat-shock protein (hsp)" y la sintasa de óxido nítrico inducible (iNOS), aumentan durante este período de isquemia como también durante la reperfusión.

En la mitocondria, la ausencia de oxígeno aumenta los niveles de ácidos grasos no esterificados como resultado del cese de su oxidación. La interrupción del ciclo de Krebs, permite la acumulación de NADH en el citoplasma, con un incremento de la relación $\mathrm{NADH} / \mathrm{NAD}^{+}$. La disminución de la oxidación produce la pérdida del potencial de membrana mitocondrial, acompañado de la disminución de la actividad de transportador (uniporter) de $\mathrm{Ca}^{2+}$ mitocondrial. La sintasa de ATP empieza a funcionar como ATPasa y contribuye a la disminución del $50 \%$ del ATP en la isquemia. La actividad del complejo I y III disminuye generando especies reactivas derivadas del oxígeno (EROs) durante la isquemia. Durante la reperfusión, el tejido isquémico reperfundido desarrolla una hiperemia reactiva muy marcada. Así, durante los primeros minutos de la reperfusión se produce una gran cantidad de EROs, que alcanzan su máximo nivel entre los 4 y $7 \mathrm{~min}$. El poro de transición mitocondrial (PTM), un mega-canal multiprotéico que conecta la matriz mitocondrial con el citosol, se abre durante la reperfusión e induce muerte celular. El pool de nucleótidos de adenina se convierte en un 90\% a ATP por medio de la refosforilación del ADP y AMP. El lactato disminuye debido su remoción por la circulación sistémica o por su oxidación a $\mathrm{CO}_{2} \mathrm{y}_{2} \mathrm{O}$. El pH retorna rápidamente a los niveles basales. Los niveles de glucosa se elevan 4 a 6 veces sobre lo normal, muy probablemente porque los transportadores GLUT-4 se desplazaron desde el sarcoplasma al sarcolema, 
durante la isquemia. A nivel de la cadena transportadora de electrones, la reperfusión daña las actividades de los complejos I y III. Además se ha observado un aumento del desacoplamiento del metabolismo mitocondrial, lo que se manifiesta como un exceso de oxidación de sustrato en comparación a la producción de energía, disminuyendo la eficacia metabólica en corazones reperfundidos.

Aún cuando los procesos de isquemia y reperfusión involucran un gran número de moléculas y procesos celulares, el daño asociado a la isquemia y reperfusión miocárdica se puede resumir en dos probables mecanismos que se relacionan entre sí (Figura 2). El primero corresponde al aumento del $\mathrm{Ca}^{2+}$ intracelular por cambios en canales y transportadores de membrana y el segundo al aumento en la producción y acumulación de EROs, que provocan peroxidación de la membrana celular, perdida de la integridad celular, facilitando la entrada de $\mathrm{Ca}^{2+33,34}$. En ambos casos, el resultado final es una hipercontractura del cardiomiocito que lo llevará irreversiblemente a su muerte por distintas vías. En las últimas décadas, existe evidencia que relaciona la apertura del PTM con la muerte celular. La apertura masiva del poro provoca depolarización mitocondrial, edema y ruptura de la membrana externa de la mitocondria, alterando irreversiblemente su función ${ }^{35-37}$. Durante la isquemia, el PTM se encuentra cerrado debido a la acidosis generada, pero durante la reperfusión se establecen condiciones que favorecen su apertura. La hipercalcemia, el estrés oxidativo y la normalización del $\mathrm{pH}$ inducen muerte celular, dependiendo de la disponibilidad de ATP ${ }^{37-39}$. La célula ejecuta el programa de apoptosis cuando sus niveles son altos, mientras que se desarrolla el de

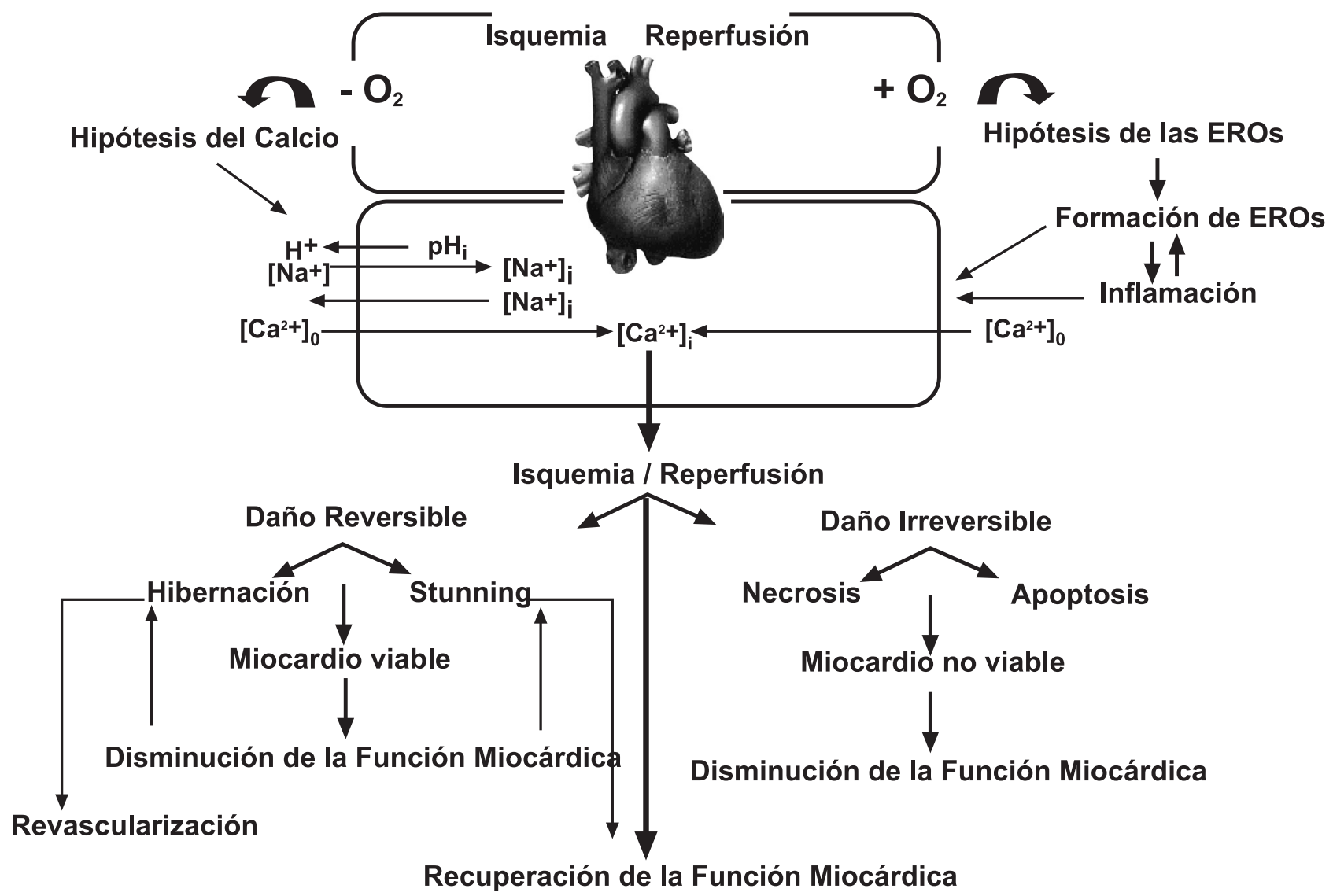

Figura 2: Hipótesis del daño por isquemia/reperfusión 
necrosis cuando hay ausencia de ATP ${ }^{40}$.

\section{Cardioprotección perioperatoria}

Precondicionamiento y postcondicionamiento isquémico, condicionamiento farmacológico e Integración de vías moleculares

En enfermos coronarios, el daño por isquemia y reperfusión se presenta en diversos escenarios clínicos tales como: la trombolisis coronaria percutánea, durante el desarrollo de cirugía de by-pass coronario, en la recuperación de un paro cardíaco o durante el período perioperatorio de gran cirugía. La severidad del daño, en cualquiera de estos casos, depende en gran medida de cuan oportunamente se logre la reperfusión de los territorios isquémicos. Se ha observado que un potencial factor que influye en el mayor o menor daño miocárdico, es la capacidad intrínseca del corazón de generar respuestas de sobrevida celular. Este hecho es clínicamente evidente en pacientes que sufren de isquemia miocárdica crónica $\circ$ que presentan isquemia subaguda prolongada. En ellos ocurre una condición de disfunción ventricular conocida como corazón hibernante $^{41}$. En estas condiciones, no se observa necrosis ni apoptosis en los territorios isquémicos, aunque sí existe una alteración de la función contráctil del miocardio. Este hecho inicialmente descrito en 1978, no se consideró relevante hasta que Rahimtoola et al demostraron que al mejorar la perfusión de los territorios isquémicos mediante cirugía de revascularización miocárdica, la disfunción del miocardio afectado se recupera ${ }^{42}$. Aparentemente los cardiomiocitos disminuirían su metabolismo y función proporcionalmente a la disminución del flujo coronario.

En el mismo sentido, se ha demostrado que frente a eventos de isquemia y reperfusión únicos, de corta duración, en que no se alcanza a producir muerte celular, el miocardio afectado presenta un déficit prolongado de la función contráctil. Este suceso conocido como "stunning" miocárdico o miocardio atontado, descrito por primera vez por Heyndrickx et al, se observa en la periferia de infartos en corazones humanos ${ }^{43}$. El corazón atontado también se presenta después del ejercicio en pacientes con estenosis coronarias parciales, en el corazón post by-pass coronario o en cuadros de espasmo coronario de paciente jóvenes. Tanto en el corazón atontado como hibernante ocurren cambios funcionales que son similares y que tienen relación con una pérdida transitoria de la función contráctil y una disminución del metabolismo celular que se recupera lentamente, toda vez que el flujo sanguíneo se restablece. En ambos casos hay ausencia de apoptosis y/ o necrosis y se gatilla una respuesta genómica caracterizada por una up-regulación de genes implicados en sobrevida, resistencia a la apoptosis y crecimiento celular ${ }^{44-46}$. Estas evidencias sugieren fuertemente que el corazón hibernante y atontado desarrollan potentes mecanismos citoprotectores frente a la isquemia y pueden relacionarse en forma mecanística con el precondicionamiento isquémico $(\mathrm{PCl})$. El PCl representa una forma de cardioprotección frente al daño por isquemia y reperfusión, que se obtiene por ciclos breves y repetidos de oclusión/ reperfusión realizados inmediatamente previo a un episodio de isquemia prolongado. Descrito por primera vez por Murry et al, representa actualmente el "gold estándar" de la cardioprotección, ya que probablemente es el mecanismo conocido más poderoso para reducir el tamaño de los infartos en modelos de isquemia y reperfusión miocárdica ${ }^{47}$. El PCI presenta dos ventanas protectoras. La primera, o temprana, confiere protección por 1 ó 2 h posterior a la isquemia y representa la adaptación de vías moleculares específicas asociadas a sobrevida y al empleo de moléculas preexistentes dentro de la célula ${ }^{48}$. La segunda ventana o tardía entrega protección por 24 a 72 h e implica la expresión de genes relacionados con sobrevida y adaptación celular ${ }^{49,50}$. Sin embargo, a pesar del poder cardioprotector del PCl, su aplicación clínica se encuentra limitada a los 
pacientes sometidos a cirugía cardíaca, puesto que requiere de una intervención mecánica previo al desarrollo de la isquemia. Es así como en pacientes que están cursando con un infarto o con una isquemia "no programada" o que están recuperándose de un paro cardíaco, una estrategia de cardioprotección basada en $\mathrm{PCl}$ se hace impracticable.

En el año 2003, se describió por primera vez el post-condicionamiento isquémico (PostCl), que es una técnica de cardioprotección que se aplica en el momento de la reperfusión y que ha demostrado resultados similares al $\mathrm{PCl}$ en reducir el tamaño de infartos en diferentes modelos animales ${ }^{51}$. Consiste en realizar ciclos breves y repetidos de oclusión/ reperfusión al inicio de la reperfusión miocárdica. La técnica ha sido usada con éxito en humanos sometidos a angioplastía en infarto agudo al miocardio ${ }^{52}$. Sin embargo, una vez más, pareciera ser que la técnica es limitada a ese escenario clínico en particular.

Sin importar cuán limitada pudiese parecer la aplicabilidad clínica del $\mathrm{PCl}$ y del PostCl, ambas técnicas han sido estudiadas en un intento por desentrañar los mecanismos moleculares tempranos y tardíos que confieren cardioprotección. Un punto a destacar es el hecho de que la maquinaria transduccional activada durante el $\mathrm{PCl}$ es similar a la maquinaria activada durante el PostCl ${ }^{53-55}$. De esta manera, existe una vía transduccional de protección miocárdica común a ambas estrategias cardioprotectoras, que corresponde a varias kinasas relacionadas con sobrevida, agrupadas dentro de lo que se conoce como vía RISK ("Reperfusion Injury Salvage Kinases") o vía de proteínas kinasas

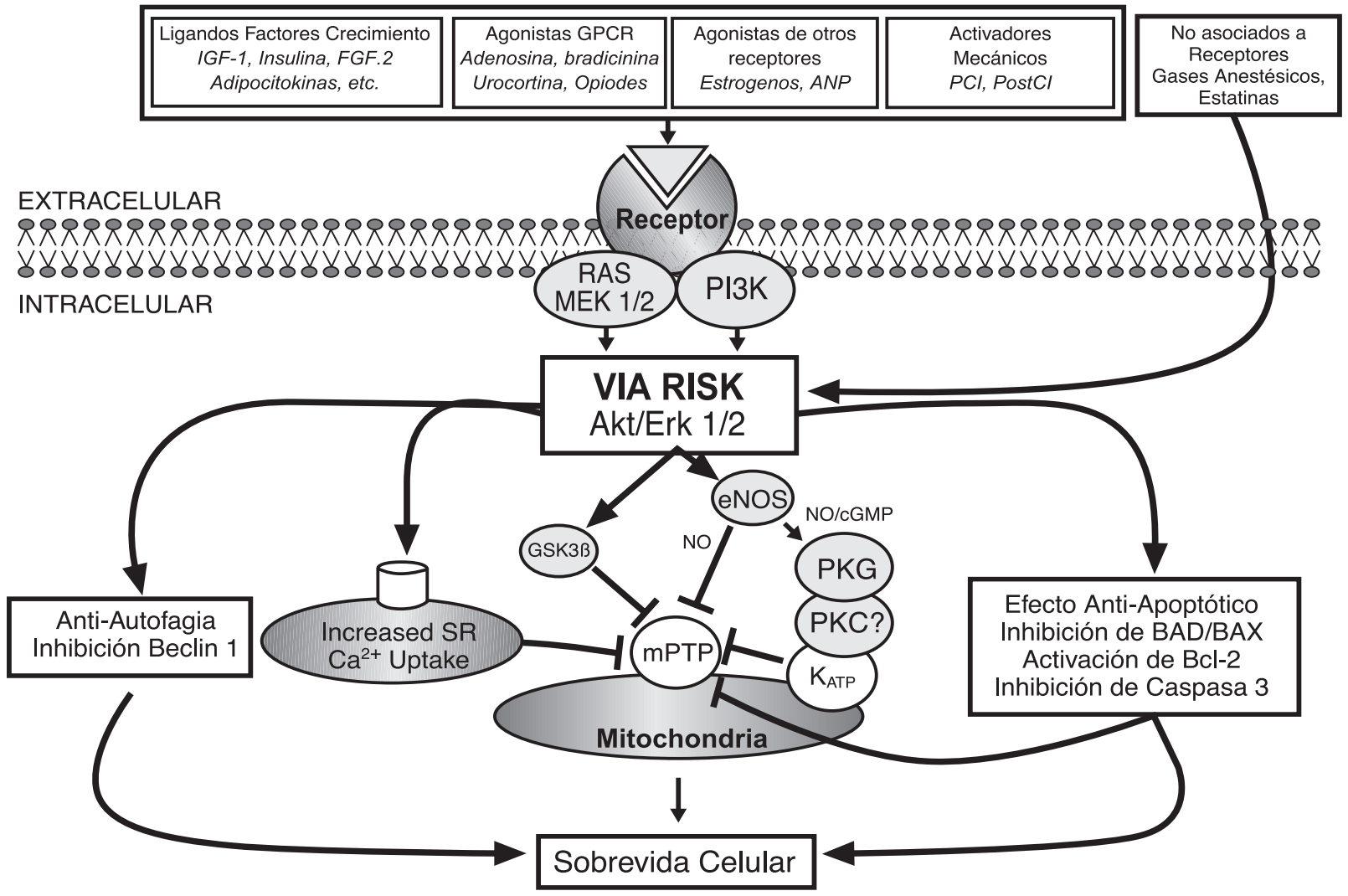

Figura 3: Vía transduccional RISK 
de salvatage del daño inducido por reperfusión 56,57 (Figura 3).

La vía RISK surgió como concepto en los últimos años de la década de los 90 , unido al reconocimiento de la apoptosis como mecanismo de muerte en el daño por reperfusión. Los integrantes originales de la vía eran fosfatidilinositol 3-kinasa (PI3-K), proteína kinasa B (Akt) y proteína kinasa regulada extracelularmente tipos 1 y 2 (ERK1/2), que al ser activadas durante la reperfusión conferían una potente cardioprotección. Durante eventos de isquemia y reperfusión, estas proteínas kinasas se activan normalmente, pero en niveles insuficientes para producir cardioprotección. Se requiere de un estímulo más potente ya sea mecánico ( $\mathrm{PCl}$ o PostCl) o farmacológico para conferir protección. Actualmente, la vía incluye a una serie de otras proteínas kinasas tales como: proteína kinasa $\mathrm{C}$ epsilon (PKC- $\varepsilon$ ), proteína kinasa dependiente de GMP cíclico (PKG), p70 s6K y GSK-3ß. Como efector final, la vía converge en el PTM, manteniéndolo cerrado. El mecanismo por el cual la cascada de kinasas logra inhibir la apertura de PTM en los primeros minutos de la reperfusión, aún no está del todo claro. Sin embargo, pareciera estar relacionado con la actividad y fosforilación de algunos componentes río abajo en la vía, como por ejemplo GSK-3 $\beta$, cuya fosforilación e inhibición confiere protección. Otro componente relacionado con este efecto modulador del PTM es la óxido nítrico sintasa endotelial (eNOS) que puede inhibir al poro al activar a la vía PKG-PKC y la apertura de canales mitocondriales de potasio dependientes de ATP (mKATP) o en forma directa por acción del NO. Otro potencial mecanismo modulador del PTM es la inhibición de la translocación de BAX a la mitocondria. Recientemente se ha descrito la reducción del $\mathrm{Ca}^{2+}$ intracelular al estimularse su captación por el retículo sarcoplásmico. Este efecto estaría mediado por la actividad de Akt. La vía RISK modula además otros componentes asociados al daño por isquemia y reperfusión como son la producción de EROs, la sobrecarga de $\mathrm{Ca}^{2+}$ y el pH post-isquémico. Es sabido y aceptado que la elevada producción de EROs durante la isquemia y especialmente durante la reperfusión, se asocia con mayor daño miocárdico.

Durante el $\mathrm{PCl}$ y PostCl, la producción de EROs se atenúa considerablemente pero se mantiene. Los
EROs generan protección; es decir, cierta cantidad de EROs son necesarios para generar respuestas de sobrevida al ser mediadores de señales de vías transduccionales protectoras. Esta contradicción de daño/protección asociada a los EROs podría explicarse por diferencias en la compartamentalización de éstos (citosólicos versus mitocondriales), el momento en que son generados (durante la isquemia versus la reperfusión), el tipo de EROs $\left(\mathrm{O} \cdot \mathrm{y} \mathrm{H}_{2} \mathrm{O}_{2}\right.$ versus $\mathrm{OH} \cdot$ ) y obviamente la cantidad (pocos versus muchos). Recientemente se ha establecido una relación entre EROs mitocondriales ya que al modular la actividad de PKC- $\varepsilon$, potenciarían la apertura de mKATP e inhibirían la apertura del PTM. Por otro lado, reducir los niveles de $\mathrm{Ca}^{2+}$ intracelular e intramitocondrial pareciera ser beneficioso dado que previene la muerte celular porque evita la apertura del PTM o la hipercontractura del cardiomiocito. Tanto el $\mathrm{PCl}$ como el PostCl producen este efecto. La inhibición del intercambiador de $\mathrm{Na}^{+} / \mathrm{H}^{+}$por el $\mathrm{PCl}$ no sólo permitiría que la corrección del pH fuera más lenta durante la reperfusión evitando la apertura del PTM, sino que también influiría en la disminución de la entrada de $\mathrm{Ca}^{2+}$ al intracelular. Aún más trascendente que el hecho de que esta vía transduccional sea activada por maniobras de $\mathrm{PCl} o$ PostCl, es la certeza que esta vía puede ser gatillada por distintas moléculas, hormonas y/o fármacos en intensidades variables, introduciendo el concepto de pre y postcondicionamiento farmacológico ${ }^{56,57}$. Está bien establecido que el estímulo de receptores de membrana asociados a proteína G (GPCR), por ligandos endógenos tales como adenosina, bradicininas y opiodes, puede iniciar la activación de esta vía de protección celular. Existe evidencia que la activación de receptores de adenosina $A_{2 A}$ y $A_{3}$, tanto en la etapa de isquemia como durante la reperfusión, es fundamental para conferir protección por la vía RISK ${ }^{58,59}$. Fármacos tales como opiodes, anestésicos inhalatorios y estatinas son cardioprotectores al activar de una u otra forma la vía RISK. En este punto es importante diferenciar entre fármacos cardioprotectores de aquellos que tienen propiedades pre o postcondicionantes. Los primeros hacen referencia al desarrollo de protección miocárdica en tanto el fármaco esté presente en concentraciones plasmáticas circulantes 
efectivas, pero cuyo efecto protector se pierde en ausencia del fármaco. Diferente es el concepto de condicionamiento, que implica que la protección miocárdica no se pierde en ausencia del fármaco, sino que se mantiene aún cuando no sea detectable en la circulación. Esto tiene relación con generar protección en las ventanas tempranas (activación de vías cardioprotectoras) y tardías (cambios en transducción génica) de cardioprotección.

Este concepto de farmacoprotección y condicionamiento cardíaco está cada vez más difundido y se utiliza clínicamente en situaciones de manejo de pacientes con alto riesgo cardiovascular sometidos a procedimientos terapéuticos, ya sean médicos o quirúrgicos. En cirugía cardíaca y no cardíaca de pacientes coronarios, se pregona el uso de fármacos cardioprotectores para evitar la ocurrencia de eventos coronarios agudos y disminuir los daños asociados a isquemia y reperfusión coronaria.

\section{Cardioprotección por dexmedetomidina}

La dexmedetomidina es un potente agonista de receptores $\alpha$-adrenérgicos con alta selectividad por $\alpha_{2}$ y ocho veces más específico que clonidina. Tiene un volumen de distribución relativamente grande de $200 \mathrm{~L}$ con un perfil farmacocinético no-lineal. Es metabolizada por el hígado a través del sistema citicromo P-450 y eliminada por el riñón. En clínica se utiliza en sedación perioperatoria y cuidados intensivos, debido a sus efectos analgésicos y ansiolíticos. Se administra vía endovenosa, ya sea como un bolo único de aproximadamente $1 \mu \mathrm{g} / \mathrm{kg}$ o más comúnmente como bolo más una infusión continua que oscila entre $0,2-1 \mu \mathrm{g} / \mathrm{kg} / \mathrm{h}$. El estímulo de los distintos subtipos de receptores $\alpha_{2}$ adrenérgicos $\left(\alpha_{2 A}, \alpha_{2 B}, \alpha_{2 C}\right)$ y su ubicación en el sistema nervioso (pre o postsináptico), determinará los distintos efectos cardiovasculares observados durante su uso. Un bolo endovenoso de dexmedetomidina en individuos sanos determina una respuesta bifásica de la presión arterial, con un aumento transitorio inicial, atribuible a la activación de receptores $\alpha_{2 B}$ postsinápticos que inducen vasoconstricción en la musculatura lisa vascular, seguido de una disminución de la presión arterial y frecuencia cardíaca, producto de la simpatolisis inducida por la activación de receptores $\alpha_{2 A}$ en el sistema nervioso central. Además, el estímulo de receptores $\alpha_{2}$-adrenérgicos postsinápticos en células endoteliales produciría vasodilatación. Esta acción aparentemente dual del fármaco se hace evidente cuando se considera su efecto en territorios simpáticamente denervados, como por ejemplo, en un bloqueo anestésico de nervios periféricos o cuando es usada en altas dosis. En estas situaciones predomina el efecto vasoconstrictor periférico de la droga, efecto opuesto a la vasodilatación descrita

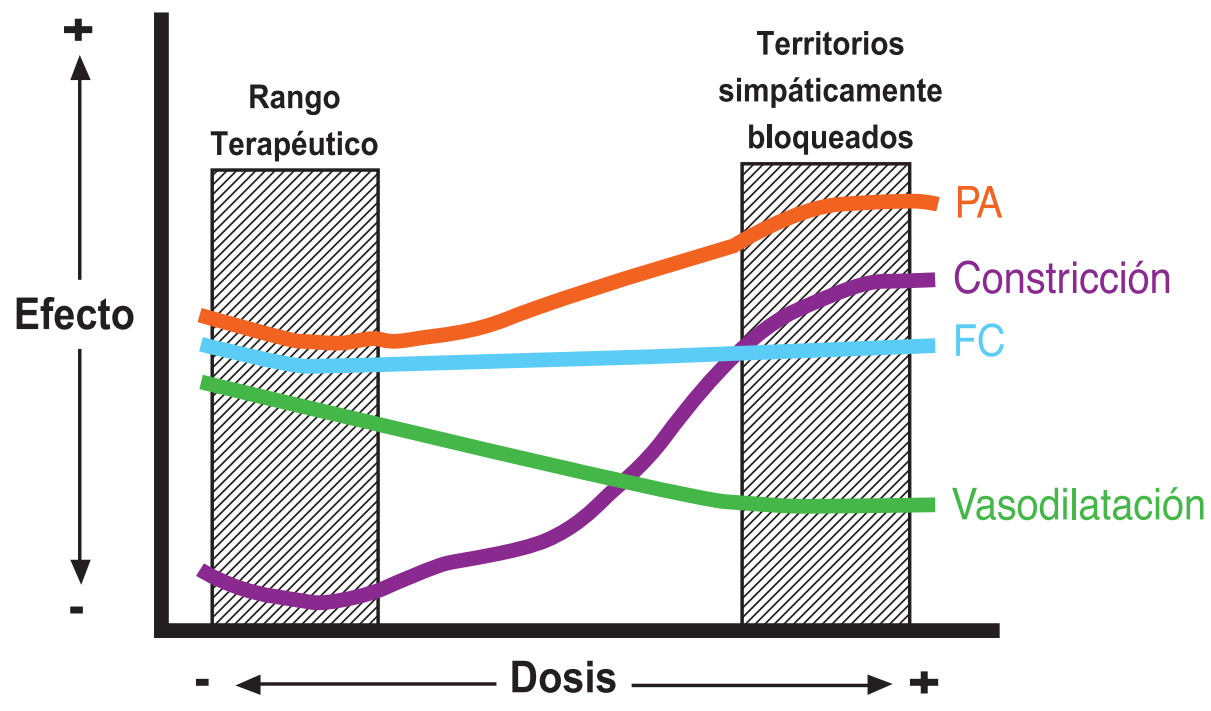

Figura 4: Cambios hemodinámicos con dexmedetomidina 
cuando se emplean dosis bajas o se usa en sujetos con el sistema simpático no intervenido ${ }^{60}$ (Figura 4).

En este escenario no es sencillo predecir los efectos cardiovasculares del fármaco en un paciente particular, especialmente si consideramos la dosis empleada y la velocidad de infusión con que es administrada. La Tabla 1 resume los efectos endocrinos y cardiovasculares observados en pacientes sanos, destacando la disminución del tono simpático, del flujo coronario y en forma paralela el trabajo miocárdico. Es esta capacidad de modulación del sistema nervioso simpático, lo que ayudaría a mantener el balance en la relación aporte/demanda de oxígeno miocárdico, impactando de manera favorable en la morbi-mortalidad perioperatoria en cirugía vascular y cardíaca.

Tabla 1: Cambios hemodinámicos en pacientes sanos.

\begin{tabular}{lcc}
\hline & $\begin{array}{c}\text { Dexmedetomidina } \\
\text { dosis bajas } \\
\text { (rango terapéutico) }\end{array}$ & $\begin{array}{c}\text { Dexmedetomidina } \\
\text { dosis altas } \\
\text { (sobre rango terapéutico) }\end{array}$ \\
\hline Gasto Cardiaco & $\downarrow 2 \%$ & $\downarrow 15 \%$ \\
Frecuencia Cardiaca & $\downarrow 10 \%$ & $\downarrow 20 \%$ \\
Presión Arterial Sistólica & $\downarrow 20 \%$ & $\downarrow 5 \%$ \\
Presión Arterial Diastólica & $\downarrow 15 \%$ & $\uparrow 20 \%$ \\
Presión Pulmonar Sistólica & $\downarrow 20 \%$ & $\uparrow 30 \%$ \\
Presión Pulmonar Diastólica & $\downarrow 20 \%$ & $\uparrow 25 \%$ \\
Flujo Sanguineo Coronario & $\downarrow 27 \%$ & $\downarrow 27 \%$ \\
Resistencia Vascular Sistémica & $\uparrow 15 \%$ & $\uparrow 60 \%$ \\
Resistencia Vascular Coronaria & $\uparrow 20 \%$ & $\uparrow 50 \%$ \\
Producto F·P (demanda O2 miocárdico) & $\downarrow 23 \%$ & $\downarrow 23 \%$ \\
Niveles plasmáticos Norepinefrina & $\downarrow 35 \%$ & $\downarrow 35 \%$ \\
Niveles Plasmáticos Epinefrina & $\downarrow 30 \%$ & $\downarrow 30 \%$ \\
\hline
\end{tabular}

Adaptado desde Hogue et al. (2002), Snapir et al. (2006), Kato et al. (2009).

\section{Evidencia experimental}

Estudios en animales sugieren que dexmedetomidina posee propiedades cardioprotectoras. Perros sometidos a estenosis fija de la arteria coronaria descendente anterior evidenciaron una menor incidencia de isquemia y menor producción de lactato durante el período de estudio, en el grupo usuario de dexmedetomidina versus el grupo control ${ }^{61}$.

En otro estudio realizado también en perros, dexmedetomidina suprimió la respuesta endocrina y cardiovascular frente a un estímulo simpático ${ }^{62}$.

A la fecha se acepta que de existir la cardioprotección mediada por el uso del fármaco, se debe en gran medida a la modulación que ejerce a nivel central sobre el SNA al disminuir el tono simpático. Ahora bien, en ausencia de la influencia del sistema neurovegetativo, existe evidencia que sugiere que dexmedetomidina entregaría protección miocárdica no mediada por neuromodulación exclusiva, sino que podrían existir otros mecanismos de cardioprotección mediada por estimulación de receptores $\alpha_{2}$ adrenérgicos postsinápticos en el corazón, frente a isquemia y reperfusión global. En corazones aislados (sin influencia del sistema nervioso central) de ratas sometidos a hipoxia y reoxigenación miocárdica global, el uso de dexmedetomidina previo y durante los eventos hipóxicos mejorólafunciónventricularyelflujocoronario,comparado con el grupo control ${ }^{63}$. Según los autores, este efecto benéfico podría atribuirse a estímulo de receptores $\alpha_{2}$ adrenérgicos, al perderse el efecto cardioprotecctor 
con el uso de yohimbina. Okada et a/64 concluyeron que dexmedetomidina tiene un efecto cardioprotector en la isquemia global de corazones aislados de rata, mediado por estimulación de receptores $\alpha_{2}$ adrenérgicos postsinápticos que causarían vasoconstricción coronaria y protección de forma similar al $\mathrm{PCl}$. El trabajo de Okada es el primero en sugerir un probable efecto precondicionador de dexmedetomidina. En ese sentido, hay evidencia que dexmedetomidina aumentaría significativamente la producción de NO a partir de células endoteliales, en concentraciones suficientes como para generar protección miocárdica por esa vía ${ }^{65}$. Sin embargo, hasta este momento ningún estudio ha explorado los potenciales mecanismos moleculares de cardioprotección generados por el medicamento y se desconoce si dexmedetomidina gatilla vías moleculares cardioprotectoras con activación de kinasas de sobrevida celular que forman parte de la vía RISK.

\section{Evidencia clínica}

No existe a la fecha ningún estudio clínico prospectivo, randomizado, con un tamaño muestral adecuado que haya estudiado directamente los beneficios de dexmedetomidina, sobre outcomes cardiovasculares asociados a isquemia miocárdica y sus complicaciones. Existen sí, numerosos estudios diseñados para definir efectos anestésicos, hemodinámicos y neuromoduladores de la dexmedetomidina, en los cuales se hace referencia a la ocurrencia o no de eventos cardiovasculares (Tabla 2).

TABLA 2. Meta-análisis que incluyen Dexmedetomidina.

\begin{tabular}{|c|c|c|c|c|c|c|c|c|c|c|c|}
\hline \multirow[t]{2}{*}{ Autor } & \multirow[t]{2}{*}{$\begin{array}{l}\text { Años } \\
\text { Incluidos }\end{array}$} & \multirow[t]{2}{*}{$\begin{array}{c}\mathrm{N} \\
\text { Total }\end{array}$} & \multicolumn{3}{|c|}{$\begin{array}{c}\text { Isquemia } \\
\text { Pacientes con Dex }\end{array}$} & \multicolumn{3}{|c|}{$\begin{array}{l}\text { Infarto Perioperatorio } \\
\text { Pacientes con Dex }\end{array}$} & \multicolumn{3}{|c|}{$\begin{array}{c}\text { Mortalidad } \\
\text { Pacientes con Dex }\end{array}$} \\
\hline & & & $n$ & $\begin{array}{c}\text { Tipo } \\
\text { Cx }\end{array}$ & $\begin{array}{c}\text { OR } \\
\text { (IC95) }\end{array}$ & $n$ & $\begin{array}{c}\text { Tipo } \\
\text { Cx }\end{array}$ & $\begin{array}{c}\text { OR } \\
\text { (IC95) }\end{array}$ & $n$ & $\begin{array}{c}\text { Tipo } \\
\text { Cx }\end{array}$ & $\begin{array}{l}\text { OR } \\
\text { (IC95) }\end{array}$ \\
\hline $\begin{array}{l}\text { Wijeysundera } \\
\text { et al. }(2003)^{C}\end{array}$ & $1966-2002$ & 3395 & 223 & $\begin{array}{l}\mathrm{C}: 80 \% \\
\mathrm{NC}: 20 \%\end{array}$ & $\begin{array}{c}0,85 \\
(0,57-1,27)\end{array}$ & 202 & $\begin{array}{l}\text { C: } 80 \% \\
\text { NC: } 20 \%\end{array}$ & $\begin{array}{c}0,47 \\
(0,11-2,03)\end{array}$ & 293 & $\begin{array}{l}\text { C: } 60 \% \\
\text { NC: } 40 \%\end{array}$ & $\begin{array}{c}0,57 \\
(0,17-1,88)\end{array}$ \\
\hline $\begin{array}{l}\text { Biccard } \\
\text { et al. }(2008)^{a}\end{array}$ & $1966-2007$ & 840 & 148 & NC: $100 \%$ & $\begin{array}{c}0,65 \\
(0,26-1,63)\end{array}$ & 152 & NC: $100 \%$ & $\begin{array}{c}0,26 \\
(0,04-1,60)\end{array}$ & 41 & NC: $100 \%$ & $\begin{array}{c}0,27 \\
(0,01-7,13)\end{array}$ \\
\hline $\begin{array}{l}\text { Wijeysundera } \\
\text { et al. }(2009)^{\mathrm{C}}\end{array}$ & $1950-2008$ & 4578 & 273 & $\begin{array}{l}\text { C: } 80 \% \\
\text { NC: } 20 \%\end{array}$ & $\begin{array}{c}0,71 \\
(0,48-1,05)\end{array}$ & 525 & $\begin{array}{c}\text { C: } 88 \% \\
\text { NC: } 12 \%\end{array}$ & $\begin{array}{c}0,68 \\
(0,24-1,87)\end{array}$ & 783 & $\begin{array}{l}\text { C: } 58 \% \\
\text { NC: } 42 \%\end{array}$ & $\begin{array}{c}1,0 \\
(0,4-2,54)\end{array}$ \\
\hline
\end{tabular}

${ }^{\mathrm{C}}$ Meta-análisis de $\alpha_{2}$-agonistas. ${ }^{\mathrm{a}}$ Meta-análisis de Dexmedetomidina.

Estos estudios han servido de sustento para la realización de al menos tres recientes metaanálisis en los que se exploran las capacidades cardioprotectoras de dexmedetomidina en la cirugía no-cardíaca. Wijeysundera at a/14,15 realizaron dos meta-análisis destinados a determinar la capacidad cardioprotectora de los agonistas $\alpha_{2}$-adrenérgicos en todo tipo de cirugías (cardíaca y no-cardíaca). El primero de ellos realizado en el 2003, incluyó 23 trabajos de los cuales 6 correspondían a estudios con dexmedetomidina (4 en cirugía no-cardíaca) y concluyó que el uso de agonistas $\alpha_{2}$-adrenérgicos en cirugía vascular disminuía significativamente la mortalidad y la incidencia de infarto perioperatorio. Sin embargo, al hacer un análisis de sub-grupos por fármaco empleado, dexmedetomidina no mostró esta diferencia. En este estudio, la incidencia de bradicardia e hipotensión, no aumentó significativamente en los tratados con agonistas $\alpha_{2-}$ adrenérgicos ${ }^{14}$.

A principios del 2009 los autores publicaron una actualización del meta-análisis previo. Usando la metodología Cochrane, incluyeron esta vez 31 trabajos de los cuales 11 correspondían a estudios con dexmedetomidina (7 en cirugía no-cardíaca).

Esta nueva revisión sistemática reveló que el uso de agonistas $\alpha_{2}$-adrenérgicos en cirugía vascular disminuye significativamente la mortalidad y la incidencia de infarto e isquemia perioperatoria. Sin 
embargo, al hacer un análisis de sub-grupos por fármaco empleado, dexmedetomidina no mostró esta diferencia. Si bien, en este estudio la incidencia de bradicardia e hipotensión aumentó significativamente en los pacientes tratados con agonistas $\alpha_{2}$-adrenérgicos, no hubo mayor incidencia de accidentes vasculares encefálicos ${ }^{15}$. En la discusión del trabajo, los autores hacen algunas reflexiones importantes de considerar: 1) parece que los efectos cardioprotectores de los agonistas $\alpha_{2}$-adrenérgicos son más evidentes en cirugía vascular comparado con otros tipos de cirugía (cardíaca o no-cardíaca-no-vascular), 2) pacientes con riesgo cardiovascular elevados se beneficiarian más del uso de agonistas $\alpha_{2}$-adrenérgicos, 3) los estudios disponibles no permiten hacer una recomendación respecto de cuál de los distintos agonistas $\alpha_{2}$ adrenérgicos disponibles (clonidina, dexmedetomidina, mivazerol) es el más adecuado para lograr una cardioprotección periporeatoria, sobre todo al considerar el riesgo de hipotensión y bradicardia asociado al uso de este tipo de fármacos, 4) muchos de los estudios incluidos eran de calidad sub-óptima, lo que pudo haber generado sesgos importantes en las conclusiones, 5) finalmente se hace notar la necesidad de contar con un estudio clínico, randomizado, controlado, con objetivos claros que permita clarificar la eficacia y seguridad de los agonistas $\mathrm{\alpha}_{2}$-adrenérgicos perioperatorios. Otro reciente meta-análisis realizado por Biccard et al. ${ }^{16}$, incluyó trabajos prospectivos de pacientes sometidos a cirugía no-cardíaca en los cuales se usó dexmedetomidina y que reportaban mortalidad y morbilidad cardíaca, sin corresponder necesariamente estos "outcomes" a los objetivos primarios planteados en la mayoría de los estudios incluidos. Biccard et al. concluyeron que el uso de dexmedetomidina se asoció con una tendencia a disminuir la mortalidad de toda causa, el infarto no fatal y la isquemia miocárdica. Sin embargo, la evidencia presentada no fue concluyente respecto de la cardioprotección entregada por dexmedetomidina. En este estudio, la incidencia de hipotensión y bradicardia aumentó significativamente con el uso de dexmedetomidina. Basado en las limitaciones del meta-análisis, el autor entrega valiosa información que intenta explicar el resultado no significativo, entre los que destacan: 1) los estudios incluidos reclutaron pacientes con escaso riesgo cardiovascular, 2) la duración de administración y la dosis de dexmedetomidina empleada en los diversos estudios fue inadecuada o insuficiente para demostrar efectos cardioprotectores, 3) los objetivos primarios en la mayoría de los estudios no contemplaban "outcomes" cardiovasculares. Según el autor estas razones justificarían la realización de un estudio clínico, randomizado, que dé cuenta de estas limitaciones.

\section{Perspectivas y conclusiones}

La patología cardiovascular, incluyendo a la enfermedad coronaria, sigue siendo la primera causa de muerte en Chile y en el mundo. En la actualidad, Chile cursa una etapa de transición demográfico-epidemiológica caracterizada por una elevada prevalencia de enfermedades cardiovasculares y de factores de riesgo cardiovascular en adultos jóvenes asociados a un envejecimiento progresivo de la población. Esta realidad provoca que en el escenario quirúrgico sea frecuente encontrar pacientes con patología coronaria y/o factores de riesgos asociados al desarrollo de isquemia miocárdica. Sabemos que la incidencia de isquemia perioperatoria se asocia a complicaciones cardiovasculares tales como: muerte, angina, infarto, arritmias, insuficiencia cardíaca. Los avances en el conocimiento de la fisiopatología y de los aspectos moleculares involucrados en la patología cardiovascular perioperatoria permiten un mejor manejo durante el perioperatorio de los pacientes quirúrgicos. La experiencia y la investigación nos han permitido descubrir que ciertas terapias farmacológicas se asocian a una disminución de eventos cardiovasculares adversos y su correlato molecular con vías de sobrevida celular. Se pregona el uso perioperatorio de fármacos con propiedades cardioprotectoras 
tales como bloqueadores $\beta$-adrenérgicos, estatinas y agonistas $\alpha_{2}$-adrenérgicos. Dexmedetomidina es un agonista $\alpha_{2}$-adrenérgico de uso frecuente en anestesia, que en diversos escenarios quirúrgicos ha mostrado una tendencia a mejorar la mortalidad, el infarto y la isquemia miocárdica. Sin embargo, su eficacia cardioprotectora, o los mecanismos moleculares involucrados en estos supuestos efectos protectores aún no están definidos. Existen escasos estudios animales que hayan explorado estos mecanismos. En el mismo sentido, existen insuficientes estudios clínicos de calidad que permitan recomendar la indicación o forma de uso de la dexmedetomidina durante el perioperatorio. Además, tomando en cuenta el aumento de hipotensión y bradicardia asociado al uso de dexmedetomidina, otro punto fundamental aún no precisado, es el perfil de seguridad del fármaco en el contexto perioperatorio de pacientes con riesgo cardiovascular. El estudio POISE con beta-bloqueadores nos mostró que estas complicaciones hemodinámicas pueden ser clínicamente relevantes al aumentar la incidencia de accidentes vasculares encefálicos ${ }^{11}$.

Será importante entonces definir la utilidad de los fármacos de uso frecuente en anestesia con potenciales capacidades cardioprotectoras disponibles en Chile y su perfil de seguridad. En este sentido, es perentorio lograr dicha definición respecto del uso de dexmedetomidina perioperatoria, mediante la realización de nuevos estudios experimentales y clínicos diseñados adecuadamente.

\section{REFERENCIAS:}

1. 2009 ACCF/AHA focused update on perioperative beta blockade incorporated into the ACC/AHA 2007 guidelines on perioperative cardiovascular evaluation and care for noncardiac surgery. J Am Coll Cardiol 2009; 54: e13-e118.

2. LEE TH, MARCANTONIO ER, MANGIONE CM, THOMAS EJ, POLANCZYK CA, COOK EF, et al. Derivation and prospective validation of a simple index for prediction of cardiac risk of major noncardiac surgery. Circulation 1999; 100: 1043-9.

3. MANGANO D. Perioperative cardiac morbidity. Anesthesiology 1990; 72: 153-84.

4. BOERSMA E, POLDERMANS D, BAX JJ, STEYERBERG EW, THOMSON IR, BANGA JD, et al. Predictors of cardiac events after major vascular surgery: role of clinical characteristics, dobutamine echocardiography and betablocker therapy. JAMA 2001; 285: 1865-73.

5. Instituto Nacional de Estadísticas (INE). Anuario de Estadísticas Vitales Año 2003.

6. Instituto Nacional de Estadísticas (INE). Mortalidad. Tablas Abreviadas por Estado Civil y Sexo. País 2001-2002.

7. República de Chile. Ministerio de Salud de Chile. Departamento de Epidemiología. Encuesta Nacional de Salud 2003.

8. BUStOS P, AMIGO H, ARTEAGA A, ACOSTA AM, RONA RJ. Factores de riesgo de enfermedad cardiovascular en adultos jóvenes. Rev Med Chile 2003; 131: 973-80.

9. PALOMO IF, TORRES GI, ALARCÓN MA, MARAGAÑO PJ, LEIVA E, MUJICA V. Alta prevalencia de factores de riesgo cardiovascular clásicos en una población de estudiantes universitarios de la región centro-sur de Chile. Rev Esp Cardiol 2006; 59: 1099-1105.

10. ACC/AHA2007 Guidelines on Perioperative Cardiovascular Evaluation and Care for Noncardiac Surgery. Circulation 2007; 116: 418-99.

11. POISE Study Group. Effects of extended-release metoprolol succinate in patients undergoing non-cardiac surgery (POISE trial): a randomised controlled trial. Lancet 2008; 371: 1813-4.

12. HINDLER K, SHAW AD, SAMUELS J, FULTON S, COLLARD CD, RIEDEL B. Improved postoperative outcomes associated with preoperative statin therapy. Anesthesiology 2006; 105: 1260-72.

13. SCHANZER A, HEVELONE N, OWENS CD, BECKMAN JA, BELKIN M, CONTE MS. Statins are independently associated with reduced mortality in patients undergoing infrainguinal bypass graft for critical limb ischemia. J Vasc Surg 2008; 4: 774-81.

14.WIJEYSUNDERA DN, NAIK JS, BEATTIE WS. Alpha-2 adrenergic agonists to prevent perioperative cardiovascular complications: A meta-analysis. Am J Med 2003; 114: 742-52.

15.WIJEYSUNDERA DN, BENDER JS, BEATTIE WS. Alpha-2 adrenergic agonists for the prevention of cardiac complications among patients undergoing surgery. Cochrane Database Syst Rev. 2009; 4: CD004126.

16. BICCARD BM, GOGA S, DE BEURS J. Dexmedetomidine and cardiac protection for non-cardiac surgery: a metaanalysis of randomised controlled trials. Anaesthesia 2008; 63: 4-14. 
17. BHANA N, GOA KL, MCCLELLAN KJ. Dexmedetomidine. Drugs 2000; 59: 263-68.

18. LANDESBERG G, MOSSERI M, ZAHGER D, WOLF Y, PEROUANSKY M, ANNER $H$, et al. Myocardial infarction after vascular surgery: the role of prolonged stress-induced, ST depression-type ischemia. J Am Coll Cardiol. 2001; 37 : 1839-45.

19. KIKURA M, OIKAWA F, YAMAMOTO K, IWAMOTO T, TANAKA KA, SATO $S$, et al. Myocardial infarction and cerebrovascular accident following non-cardiac surgery: differences in postoperative temporal distribution and risk factors. J Thromb Haemost. 2008; 6: 742-748.

20. LANDESBERG G, BEATTIE WS, MOSSERI M, JAFFE AS, ALPERT JS. Perioperative Myocardial Infarction. Circulation 2009; 119: 2936-44.

21.LE MANACH Y, PEREL A, CORIAT P, GODET G, BERTRAND M, RIOU B. Early and delayed myocardial infarction after abdominal aortic surgery. Anesthesiology 2005; 102: 885-91.

22. THYGESEN K, ALPERT JS, WHITE HD; joint ESC/ACCF/ AHA/WHT Task force for the redefinition of myocardial infarction. Universal definition of myocardial infarction. Eur Heart J 2007; 28: 2525-38.

23. LANDESBERG G, LURIA MH, COTEV S, EIDELMAN LA, ANNER H, MOSSERI M, et al. Importance of long-duration postoperative ST-segment depression in cardiac morbidity after vascular surgery. Lancet. 1993; 341: 715-9.

24. LANDESBERG G. The pathophysiology of perioperative myocardial infarction: facts and perspectives. J Cardiothorac Vasc Anesth 2003; 17: 90-100.

25. MANGANO DT, HOLLENBERG M, FEGERT G, MEYER ML, LONDON MJ, TUBAU JF, et al. Perioperative myocardial ischemia in patients undergoing noncardiac surgery: Incidence and severity during the 4 day perioperative period. J Am Coll Cardiol 1991; 17: 843-50.

26. RABY KE, BARRY J, CREAGER MA, COOK EF, WEISBERG MC, GOLDMAN L. Detection and significance of intraoperative and postoperative myocardial ischemia in peripheral vascular surgery. JAMA 1992; 268: 222-27.

27. RABY KE, BRULL SJ, TIMIMI F, AKHTAR S, ROSENBAUM $S$, NAIMI C, et al. The effect of heart rate control on myocardial ischemia among high risk patients after vascular surgery. Anesth Analg 1999; 88: 477-82.

28. FLEISHER LA, NELSON AH, ROSENBAUM SH. Postoperative myocardial ischemia: etiology of cardiac morbidity or manifestation of underlying disease?. J Clin Anesth 1995; 7: 97-102.

29. LONDON MJ, HOLLENBERG M, WONG MG, LEVENSON L, TUBAU JF, BROWNER W, et al. Intraoperative myocardial ischemia: localization by continuous 12-lead electrocardiography. Anesthesiology 1988; 69: 232-41.
30.DAWOOD MM, GUTPA DK, SOUTHERN J, WALIA A, ATKINSON JB, EAGLE KA. Pathology of fatal perioperative myocardial infarction: implications regarding pathophysiology and prevention. Int J Cardiol 1996; 57: 3744.

31. KLONER RA, GANOTE CE, WHALEN DA JR, JENNINGS $R B$. Effect of a transient period of ischemia on myocardial cells. II. Fine structure during the first few minutes of reflow. Am J Pathol 1974; 74: 399-422.

32. JENNINGS RB, MURRY CE, STEENBERGEN C JR, REIMER KA. Development of cell injury in sustained acute ischemia. Circulation 1990; 82: II2-12.

33. LEVITSKY S. Protecting the myocardial cell during coronary revascularization. Circulation 2006; 114: I-339-43.

34. RODRÍGUEZ-SINOVAS A, ABDALLAH Y, PIPER HM, GARCIA-DORADO D. Reperfusion injury as a therapeutic challenge in patients with acute myocardial infarction. Heart Fail Rev 2007; 12: 207-16.

35.DI LISA F, CANTON M, MENABÒ R, DODONI G, BERNARDI P. Mitochondria and reperfusion injury. The role of permeability transition. Basic Res Cardiol 2003; 98: 23541.

36. CROW MT, MANI K, NAM YJ, KITSIS RN. The mitochondrial death pathway and cardiac myocyte apoptosis. Circ Res 2004; 95: 957-70.

37. HALESTRAPAP, CLARKE SJ, JAVADOV SA. Mitochondrial permeability transition pore opening during myocardial reperfusion - a target for cardioprotection. Cardiovasc Res 2004; 61: 372- 85.

38. PIPER HM, GARCÍA-DORADO D, OVIZE M. A fresh look at reperfusion injury. Cardiovasc Res 1998; 38: 291-300.

39. PIPER HM, ABDALLAH Y, SCHÄFER C. The first minutes of reperfusion: a window of opportunity for cardioprotection. Cardiovasc Res 2004; 61: 365-71.

40.KIM JS, HE L, QIAN T, LEMASTERS JJ. Role of the mitochondrial permeability transition in apoptotic and necrotic death after ischemia/reperfusion injury to hepatocytes. Curr Mol Med 2003; 3: 527-35.

41.DIAMOND GA, FORRESTER JS, DELUZ PL, WYATT $\mathrm{HL}$, SWAN HJ. Post-extrasystolic potentiation of ischemic myocardium by atrial stimulation. Am Heart J 1978; 95: 204-09.

42. RAHIMTOOLA SH. A perspective on the three large multicenter randomized clinical trials of coronary bypass surgery for chronic stable angina. Circulation 1985; 72 : V123-35.

43. HEYNDRICKX GR, MILLARD RW, MCRITCHIE RJ, MAROKO PR, VATNER SF. Regional myocardial functional and electrophysiological alterations after brief coronary artery occlusion in conscious dogs. J Clin Invest 1975; 56 : 978-85. 
44. KUDEJ RK, KIM SJ, SHEN YT, JACKSON JB, KUDEJ $A B$, YANG GP, et al. Nitric oxide, an important regulator of perfusion contraction matching in conscious pigs. Am J Physiol 2000; 279: H451-56.

45.DEPRE C, TOMLINSON JE, KUDEJ RK, GAUSSIN V, THOMPSON E, KIM SJ, et al. Gene program for cardiac cell survival induced by transient ischemia in conscious pigs. Proc Natl Acad Sci USA 2001; 98: 9336-41.

46. DEPRE C, KIM SJ, JOHN AS, HUANG Y, RIMOLDI OE, PEPPER JR, et al. Program of cell survival underlying human and experimental hibernating myocardium. Circ Res 2004; 95: 433-40.

47. MURRY CE, JENNINGS RB, REIMER KA. Preconditioning with ischemia: a delay of lethal cell injury in ischemic myocardium. Circulation 1986; 74: 1124-36.

48.BAXTER GF, YELLON DM. Ischaemic preconditioning of myocardium: a new paradigm for clinical cardioprotection? Br J Clin Pharmacol 1994; 38: 381-7.

49. YELLON DM, BAXTER GF. A "second window of protection" or delay preconditioning phenomenon: future horizons for myocardial protection? J Mol Cell Cardiol 1995; 27: 102334.

50.DAS DK, MORARU II, MAULIK N, ENGELMAN RM. Gene expression during myocardial adaptation to ischemia and reperfusion. Annals N Y Acad Sci 1994; 723: 292-307.

51.ZHAO ZQ, CORVERA JS, HALKOS ME, KERENDI F, WANG NP, GUYTON RA, et al. Inhibition of myocardial injury by ischemic postconditioning during reperfusion: comparison with ischemic preconditioning. Am J Physiol 2003; 285: H579-88.

52. STAAT P, RIOUFOL G, PIOT C, COTTIN Y, CUNG TT, L'HUILLIER I, et al. Postconditioning the human heart. Circulation 2005; 112: 2143-48.

53. GROSS E, GROSS G. Ligand triggers of classical preconditioning and postconditioning. Cardiovasc Res 2006; 70: 212 -21.

54. TSANG A, HAUSENLOY DJ, MOCANU MM, YELLON DM. Postconditioning: a form of "modified reperfusion" protects the myocardium by activating the phosphatidylinositol 3-kinase-Akt pathway. Circ Res 2004; 95: 230-32.

55. HAUSENLOY DJ, TSANG A, MOCANU MM, YELLON DM.
Ischemic preconditioning protects by activating prosurvival kinases at reperfusion. Am J Physiol 2005; 288: H971-6.

56. HAUSENLOY DJ, YELLON DM. Preconditioning and postconditioning: United at reperfusion. Pharmacol Therapeutics 2007; 116: 173-91.

57. HAUSENLOY D, YELLON D. Reperfusion injury salvage kinase signalling: taking a RISK for cardioprotection. Heart Fail Rev 2007; 12:217-34.

58. KIS A, BAXTER GF, YELLON DM. Limitation of myocardial reperfusion injury by $A M P 579$, an adenosine A1/A2A receptor agonist: role of $\mathrm{A} 2 \mathrm{~A}$ receptor and Erk1/2. Cardiovasc Drugs Ther 2003; 17: 415-25.

59. PARK SS, ZHAO H, JANG Y, MUELLER RA, XU Z. N6-(3iodobenzyl)-adenosine-5'-N-methylcarboxamide confers cardioprotection at reperfusion by inhibiting mitochondrial permeability transition pore opening via glycogen synthase kinase 3 beta. J Pharmacol Exp Ther 2006; 318: 124-31.

60. TALKE P, LOBO E, BROWN R. Systemically administered $\alpha 2$-agonist-induced peripheral vasoconstriction in humans. Anesthesiology 2003; 99: 65-70.

61.WILLIGERS HM, PRINZEN FW, ROEKAERTS PM, DE LANGE S, DURIEUX ME. Dexmedetomidine decreases perioperative myocardial lactate release in dogs. Anesth Analg 2003; 96: 657-64.

62. WILLIGERS HM, PRINZEN FW, ROEKAERTS PM. The effects of esmolol and dexmedetomidine on myocardial oxygen consumption during sympathetic stimulation in dogs. J Cardiothorac Vasc Anesth 2006; 20: 364-70.

63. GUO H, TAKAHASHI S, CHO S, HARA T, TOMIYASU S, SUMIKAWA K. The effects of dexmedetomidine on left ventricular function during hypoxia and reoxygenation in isolated rat hearts. Anesth Analg 2005; 100: 629-35.

64. OKADA H, KURITA T, MOCHIZUKI T, MORITA K, SATO S. The cardioprotective effect of dexmedetomidine on global ischaemia in isolated rat hearts. Resuscitation 2007; 74 : 538-45.

65. JOSHI MS, FERGUSON TB JR, JOHNSON FK, JOHNSON RA, PARTHASARATHY S, LANCASTER JR JR. Receptormediated activation of nitric oxide synthesis by arginine in endothelial cells. Proc Natl Acad Sci USA 2007; 104: 9982-7. 